\title{
Head, face and neck injury in youth rugby: incidence and risk factors
}

EDITOR'S CHOICE
- Supplementary tables are published online only at http://bjsm.bmj.com/content/ vol44/issue 3

${ }^{1}$ School of Risk and Safety Sciences, The University of New South Wales, Sydney, New South Wales, Australia; ${ }^{2}$ Centre for Health, Exercise and Sports Medicine, University of Melbourne, Melbourne, Victoria, Australia; ${ }^{3}$ School of Human Movement and Sport Sciences, University of Ballarat, Ballarat, Victoria, Australia; ${ }^{4}$ Departmen of Epidemiology and Preventive Medicine, Monash University, Melbourne, Victoria, Australia

\section{Correspondence to:}

Andrew S Mclntosh, School of Risk and Safety Sciences, The University of New South Wales, Sydney 2052, New South Wales, Australia;

a.mcintosh@unsw.edu.au

Accepted 12 February 2008 Published Online First 2 April 2008

A S Mclntosh, ${ }^{1}$ P McCrory, ${ }^{2}$ C F Finch, ${ }^{3}$ R Wolfe ${ }^{4}$

\section{ABSTRACT}

Objectives: In this study, the incidence of head, neck and facial injuries in youth rugby was determined, and the associated risk factors were assessed.

Design: Data were extracted from a cluster randomised controlled trial of headgear with the football teams as the unit of randomisation. No effect was observed for headgear use on injury rates, and the data were pooled. Setting: General school and club-based community competitive youth rugby in the 2002 and 2003 seasons. Participants: Young male rugby union football players participating in under-13, under 15 , under 18 and under 21 years competitions. Eighty-two teams participated in year 1 and 87 in year 2.

Main outcome measures: Injury rates for all body regions combined, head, neck and face calculated for game and missed game injuries.

Results: 554 head, face and neck injuries were recorded within a total of $28902 \mathrm{~h}$ of rugby game exposure. Level of play and player position were related to injury risk.

Younger players had the lowest rates of injury; forwards, especially the front row had the highest rate of neck injury; and inside backs had the highest rate of injuries causing the player to miss a game. Contact events, including the scrum and tackle, were the main events leading to injury.

Conclusion: Injury prevention must focus on the tackle and scrum elements of a youth rugby game.

Rugby union football is a popular international team sport played by both sexes and all age groups. In recent years, there has been a focus on the injury risks in professional rugby; however, the majority of rugby participants are not professional. ${ }^{1-4}$ Internationally, there has been substantial interest in the causes and management of sporting head injuries. ${ }^{5-8}$ There are unambiguous head and neck injury risks in rugby: head injury accounts for between $15 \%$ and $30 \%$ of all injury; $15 \%$ of injury cases are concussion; serious head injuries are rare; and spinal cord injury rates are very small, but of concern because of the resultant impairment. ${ }^{1-4} 9-16$ Most of these data come from studies of adult, often professional, players and there is a need for similar data on younger players.

Data on injuries in young players are also important because parental support for sports participation is influenced by perceptions of injury risks. ${ }^{17}$ In Australia, rugby union was the second most likely sport that parents would discourage their children from playing (4\%), following rugby league $(13 \%) .{ }^{17}$ When the results were considered for boys only, $8 \%$ of parents were concerned enough to prevent participation in rugby. This paper therefore reports on head, face and neck $(\mathrm{H} /$
$\mathrm{F} / \mathrm{N}$ ) injury incidence and risk factors in youth rugby.

As often stated, there are definitional difficulties in comparing injury incidence or prevalence within and between sports. ${ }^{16}{ }^{18}$ Junge et al, in a study comparing injury in under 18 years (U18) soccer and rugby, reported for rugby a rate of 130 injury "complaints" per 1000 match hours and 28 "absence" injuries per 1000 match hours compared with 48 injury "complaints" per 1000 match hours and 16 "absence" injuries per 1000 match hours in soccer. ${ }^{19}$ Junge et al observed that $16 \%$ of rugby and $5 \%$ of soccer injuries were to the head and neck regions. ${ }^{19}$ Durie and Munroe reported the injury rate for schoolboys to be $28 / 1000 \mathrm{~h}$ with $10 \%$ of all injuries being to the head and neck. ${ }^{20}$ In men's collegiate ice hockey, an average rate of 1.47 concussions per 1000 athletic game exposures was observed and head/neck injury accounted for $15.4 \%$ of game injuries. ${ }^{21}$ In a similar cohort of men's collegiate soccer players, an average rate of 1.08 concussions per 1000 athletic game exposures was observed over a 15-year period, and head/neck injury accounted for $12.8 \%$ of all game injuries. ${ }^{22}$

Previously identified injury risk factors in rugby include age group, player position and grade within the age group, as well as phase of play/event at time of injury. ${ }^{123}$ Quarrie et al observed that the "midfield backs" missed more of the season because of injury and an increasing rate of injury for the four age divisions from under 17 years (U17) to opens. ${ }^{23}$ Quarrie et al also found that injury rates increased with increasing body mass, although this finding is confounded by age. ${ }^{23}$ This research has not been reproduced in younger rugby populations.

Therefore, this paper contributes to knowledge about $\mathrm{H} / \mathrm{F} / \mathrm{N}$ injury in rugby by presenting injury incidence data in young male players and may lead to more focussed injury prevention strategies for those populations by identifying rugby injury risk factors.

\section{METHODS \\ Study design}

Injury and player participation data from a clustered randomised controlled trial of the efficacy of headgear conducted in 2002 and 2003 were analysed..$^{24}$ Data from the three arms of the study were pooled together, as no significant differences in injury rates associated with headgear use were observed.

\section{Participants}

Male rugby players were recruited from the following levels of play: schoolboy under 13 years 
(U13), under 15 years (U15) and under 18 years (U18), and club under 20 years (U20) (also known as Colts). Clubs and schools were invited to participate by letter and followed-up by phone calls and meetings. Once agreement was reached on involvement, individual teams were contacted through their coaches, and players were invited to participate. Teams and players were not provided with incentives to participate in the study. Players or parents/guardians provided informed written consent, and the study was approved by The University of New South Wales Human Research Ethics Committee.

In the analyses presented here, the main objective was to assess the influence of the following risk factors on $\mathrm{H} / \mathrm{F} / \mathrm{N}$ injury: level of play, player position and grade. In this study, grade refers to the standard of a team within a level-for example, 1st or A grade, 2nd or B grade. The overall rates of injury were calculated and analysed for these risk factors, in order to identify whether they were general or specific to the H/ $\mathrm{F} / \mathrm{N}$. Player positions were divided into five categories: front row with two props and one hooker; back five with the two locks, number 8 and two flankers; halves with half back and flyhalf; inside backs with the two centres or wing three quarters; and outside backs with the two wings and full back.

\section{Procedures}

Two operational injury definitions were used ${ }^{18} 2526$ : (1) game injury-any injury requiring on-field treatment or resulting in the player being removed from the field during a rugby game, and (2) missed game injury-any injury occurring in a rugby game resulting in the player missing a game the next week (usually at least 7 days absence from competition). The missed game injuries are largely a subset of game injuries. In comparison to some other terminology, a game injury is equivalent to a "medical attention injury" that occurs during a game, and a missed game injury is equivalent to a "time loss injury" with the unit of time loss determined by availability to play in a game. Injury and participation data were recorded using standard methods at each game in the study by paid primary data collectors (PDCs). PDCs were university students typically studying medicine, physiotherapy or sports science. All PDCs received formal training in injury and participation registration and were supervised at games. PDCs worked closely with each team and maintained weekly team participation lists, in which the minutes played by each player, the reason for leaving the field or the reason for absence from the game was recorded. When an injury occurred, a simple standard form was completed that contained defined fields for injured body region, nature of injury and cause of injury, player details, concussion descriptors and whether the player was sent to the hospital. More detailed injury information was obtained from the player's treating doctor or physiotherapist associated with the team. Injury definitions, data collection and rate calculations conform to the recent consensus statement on this topic for rugby football, and the missed game injury definition is equivalent to at least the "moderate" severity definition of 828 lost days from competition or practice..$^{18}$ Data were entered into a database, and player absences were identified, and the causes (eg, absence due to a rugby injury, illness, relegated) were determined.

At pre-season training sessions in both years, the statures and body masses of a subset of the participants were measured by appropriately trained researchers. Not all players were measured because of time and resource limitations.

\section{Statistical methods}

Incidence rates were calculated as the number of injuries per 1000 person-hours of game time. Rates were calculated for H/F/ $\mathrm{N}$ injury, separately and combined, as well as concussion, and stratified by level of play, grade and player position. The injury event was analysed for $\mathrm{H} / \mathrm{F} / \mathrm{N}$ and combined injury. Injury event data are reported as proportions. To compare injury rates, incidence rate ratios (IRRs) were obtained from Poisson regression models. ${ }^{27}$ Robust SEs were calculated to allow for randomisation by team. ${ }^{28}$ Intracluster correlations were calculated by comparing SEs from our analysis method with SEs from an analysis that ignored the clustering. This comparison showed negligible inflation of SEs due to clustering. All analyses were undertaken using Stata software, with $p<0.05$ being statistically significant.

\section{RESULTS \\ Injury incidence}

A total of 1841 injuries were experienced by 1159 players during the two seasons. Six hundred and four missed game injuries were observed. Of the game injuries, $554(30 \%)$ were $\mathrm{H} / \mathrm{F} / \mathrm{N}$ injuries, and $81(13 \%)$ of the missed game injuries were $\mathrm{H} / \mathrm{F} / \mathrm{N}$. Within the 234 head injuries, there were 199 concussion injuries of which 47 resulted in a missed game. There were 96 neck injuries of which 21 resulted in a missed game and 224 facial injuries of which 12 resulted in a missed game. With regards to concussion symptoms, no concussed player lost consciousness for longer than $5 \mathrm{~min}$ and only $20 \%$ of players lost consciousness. Almost $50 \%$ of concussed players experienced headaches or dizziness, and $22 \%$ had limited post-traumatic amnesia. Six per cent of the concussion cases were sent to the hospital from the game. Only 16 of the 199 concussion cases (8\%) missed more than two games (14 days) of competition.

A total of 3277 players participated in at least one game from 82 teams in year 1 and 87 teams in year 2 of the study. For this analysis, injuries from a total of 1908 games were included. A total of $28902 \mathrm{~h}$ of exposure during rugby game participation was measured for the participants. There were more exposures in the U20 age group, as they played at least twice the number of games per season as the school-age players. Forty-four per cent of all exposures were in the U20s, compared with $26 \%$ in the U18s, $16 \%$ in the U15s and $14 \%$ in the U13s. With regards to grade, $39 \%$ of exposures were in first grade (As), $35 \%$ in second grade (Bs), $15 \%$ in third grade (Cs) and $12 \%$ in fourth grade (Ds).

The overall H/F/N game injury rate was $19.2 / 1000 \mathrm{~h}$ of player-game exposure, and for missed game injuries, 2.8/1000 h. The rates of concussion were 6.9 and $1.6 / 1000 \mathrm{~h}$ for game and missed game injuries, respectively. Table 1 summarises the game and missed game injury rates for the all body regions by level of play, as well as $\mathrm{H} / \mathrm{F} / \mathrm{N}$ and concussion. Rates for $\mathrm{H} / \mathrm{F} / \mathrm{N}$ injury, stratified by level and player position, are presented in the online only supplementary appendix.

\section{Baseline player characteristics}

Baseline data on body mass and height for a subset of participants stratified by level of play $(n=1409)$ are presented online only in supplementary table 1 .

\section{Risk factor analysis}

All injury regions

Unadjusted IRRs were calculated for all body regions (online only supplementary table 2). The higher the age level, the 
Table 1 Frequencies and incidence rates of game and missed game injuries (injuries per $1000 \mathrm{~h}$ of game participation) by body region, type and level of play

\begin{tabular}{|c|c|c|c|c|}
\hline & \multicolumn{2}{|c|}{ Game injuries } & \multicolumn{2}{|c|}{ Missed game injuries } \\
\hline & $\mathbf{n}$ & $\begin{array}{l}\text { Injuries per } 1000 \mathrm{~h} \\
(95 \% \mathrm{Cl})\end{array}$ & $\mathbf{N}$ & $\begin{array}{l}\text { Injuries per } 1000 \mathrm{~h} \\
(95 \% \mathrm{CI})\end{array}$ \\
\hline \multicolumn{5}{|l|}{ Body region } \\
\hline All & 1841 & 63.7 (60.9 to 66.7$)$ & 604 & 20.9 (19.3 to 22.6$)$ \\
\hline Head & 234 & 8.1 (7.1 to 9.1$)$ & 48 & $1.7(1.2$ to 2.1$)$ \\
\hline Face & 224 & 7.8 (5.1 to 10.4$)$ & 12 & $0.4(0.0$ to 1.0$)$ \\
\hline Neck & 96 & $3.3(2.7$ to 4.0$)$ & 21 & $0.7(0.4$ to 1.0$)$ \\
\hline $\mathrm{H} / \mathrm{F} / \mathrm{N}$ & 554 & 19.2 (15.0 to 23.4$)$ & 81 & 2.8 (1.2 to 4.4$)$ \\
\hline \multicolumn{5}{|l|}{ Type } \\
\hline Concussion & 199 & $6.9(4.4$ to 9.4$)$ & 47 & $1.6(0.4$ to 2.9$)$ \\
\hline \multicolumn{5}{|l|}{ Level of play } \\
\hline U20 & 946 & 73.4 (68.9 to 78.3 ) & 293 & 22.6 (20.2 to 25.4$)$ \\
\hline U18 & 461 & $63.0(57.5$ to 69.1$)$ & 162 & $22.2(19.0$ to 25.8$)$ \\
\hline U15 & 250 & 56.2 (49.6 to 63.6$)$ & 99 & 22.3 (18.3 to 27.1$)$ \\
\hline U13 & 184 & 43.3 (37.5 to 50.1$)$ & 50 & 11.8 (8.9 to 15.5$)$ \\
\hline
\end{tabular}

$\mathrm{H} / \mathrm{F} / \mathrm{N}$, head, face and neck; U13, rugby players $<13$ years; U15, rugby players $<15$ years; U18, rugby players $<18$ years; U20, rugby players $<20$ years.

greater the injury rate, with U13s having the lowest rates for both game and missed game injuries. There were significant differences in the rates of missed game injuries based on player position, with the inside backs (two player positions) having the greatest rate. There were no grade effects observed. IRR analyses for the factors player position and grade were conducted after adjustment for level of play. The IRRs were largely unchanged from the unadjusted analyses, which indicated that there was no confounding effect of level of play on the relationship between player position and injury rate.

\section{$\mathrm{H} / \mathrm{F} / \mathrm{N}$ injury}

The unadjusted IRRs for $\mathrm{H} / \mathrm{F} / \mathrm{N}$ injuries, in relation to player position, level and grade are presented in table 2 . Because of the similarities between head injury and concussion case sets, analyses for head injuries only are reported. No significant differences were observed for $\mathrm{H} / \mathrm{F} / \mathrm{N}$ game injuries, although the trend indicated lower injury rates for the U13 and U15 age groups. Analyses of rates of missed game injuries for the H/F/N showed no significant effects for level of play, grade, player position and season. Except for the effect of grade on game injury rates for the head, no other statistically significant effects were observed for head injury. There was a significant association between player position and game injuries to the face with the back five experiencing the highest rate. U13s experienced the lowest rate of facial injury. The analysis of game injuries to the neck showed a significant association with player position and injury. The front row had the greatest rate of injury, and the backs had a significantly lower rate of neck injury compared with the front row as reference. All missed game neck injuries occurred to forwards; due to this and the low absolute number of injuries, a statistical analysis was not possible. No significant differences were observed based on analyses of grade or level for neck injuries at games. IRR analyses were largely unchanged after adjustment for level of play.

The main event in rugby leading to $\mathrm{H} / \mathrm{F} / \mathrm{N}$ injury was the tackle. The distribution of $\mathrm{H} / \mathrm{F} / \mathrm{N}$ and neck injuries by inciting event is presented in table 3 .

\section{Catastrophic injury}

No catastrophic injury was observed in this cohort, but two players had odontoid fractures without neurological injury.
Both players were flankers; one played in the U20 age group, the other U15, and both ceased participation in rugby as a result of the injury. The older player was injured in a tackle while defending. Before contact, he reported being "flat footed". He struck the ball carrier with his head, and his neck was in a flexed position. The younger player was injured in a ruck that collapsed on top of him causing his head to be forced forward across onto his left shoulder, which resulted in an audible crack. The players did not exhibit any neurological signs and were permitted to leave the ground by private transport.

\section{DISCUSSION}

The results of this study have identified $\mathrm{H} / \mathrm{F} / \mathrm{N}$ injury incidence rates and risk factors in a cohort of youth rugby. The analyses presented were undertaken on data from a randomised controlled trial of headgear in rugby union football. Five hundred and fifty-four $\mathrm{H} / \mathrm{F} / \mathrm{N}$ injuries were recorded in two seasons of rugby union during $28902 \mathrm{~h}$ of player game exposure. The overall $\mathrm{H} / \mathrm{F} / \mathrm{N}$ injury incidence rates were comparable to other rugby studies, although slightly higher than reported in similar youth populations. ${ }^{19} 20$

\section{Limitations}

Sports injury studies are complex and require the coordination and cooperation of many individuals to collect basic participation and injury data. The collection of participation data is generally straight forward, especially when a PDC is attached to a team during the season and is familiar with each player. As has been observed by many authors, the operational definition of injury determines the level of PDC skill and player contact required, and the resultant injury rates and patterns. In this study, PDC were not sports medicine experts, and the injury details collected were limited to a predefined set describing anatomical region, nature of injury and injury event. As described below, the collection of additional risk factor data would have enhanced the study, although clearly substantial resources are required to undertake physical, medical and psychological measures or a very large cohort.

\section{Injury risk factors}

General injury risk factors were level of play and player position. As the age level increased from the U13s, the injury incidence 
Table 2 Unadjusted IRRs according to level of play, player position and grade for head, face and neck (H/F/N) injuries separately and combined

\begin{tabular}{|c|c|c|c|c|c|c|c|c|}
\hline & \multicolumn{4}{|l|}{ Game injuries } & \multicolumn{4}{|c|}{ Missed game injuries } \\
\hline & Head & Face & Neck & $\mathrm{H} / \mathrm{F} / \mathrm{N}$ & Head & Face & Neck & $\mathrm{H} / \mathrm{F} / \mathrm{N}$ \\
\hline \multicolumn{9}{|c|}{ Level of play } \\
\hline U18 & 0.94 (0.60 to 1.48 ) & 1.14 (0.6 to 1.91$)$ & 0.84 (0.38 to 1.84$)$ & 1.01 (0.68 to 1.49$)$ & ) 1.20 (0.64 to 2.26$)$ & ) 1.17 (0.45 to 3.02 ) & 1.32 (0.46 to 3.7$)$ & 1.22 (0.78 to 1.92$)$ \\
\hline
\end{tabular}

Player

position

FR (refl)

\begin{tabular}{|c|c|c|c|c|c|c|}
\hline $\begin{array}{l}\text { Comparisons } \\
\text { across five } \\
\text { positions, }\end{array}$ & $\begin{array}{l}\text { Comparisons } \\
\text { across five } \\
\text { groups, }\end{array}$ & $\begin{array}{l}\text { Comparisons } \\
\text { across five groups, } \\
p=0.0002\end{array}$ & $\begin{array}{l}\text { Comparisons } \\
\text { across five } \\
\text { groups, }\end{array}$ & $\begin{array}{l}\text { Comparisons } \\
\text { across five } \\
\text { positions, }\end{array}$ & $\begin{array}{l}\text { Comparisons } \\
\text { across five } \\
\text { groups, }\end{array}$ & $\begin{array}{l}\text { Comparisons } \\
\text { across five groups, } \\
\mathrm{p}=0.25\end{array}$ \\
\hline
\end{tabular}

B5 $\quad 1.27$ (0.87 to 1.84$) 1.55$ (1.1 to 2.07$) \quad 0.85$ (0.55 to 1.326$) 1.25$ (1.02 to 1.53$) 1.37$ (0.53 to 3.58$) 0.30$ (0.02 to 4.95 )

$1.09(0.52$ to 2.29$)$

1.77 (1.06 to 2.96$) \quad 1.07(0.6$ to 1.79$) \quad 0.25(0.11$ to 0.55$) \quad 1.08$ (0.80 to 1.47$) 1.45$ (0.55 to 3.85$) 0.72$ (0.04 to 12.1$)$

$0.68(0.29$ to 1.62$)$

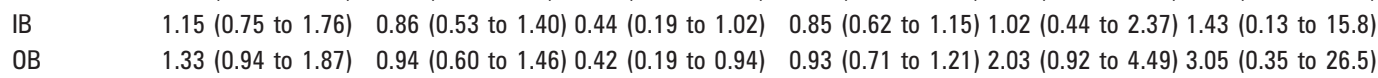

0.59 (0.26 to 1.33$)$

$1.20(0.65$ to 2.21$)$

Grade

A (ref)

\begin{tabular}{|c|c|c|c|c|c|}
\hline $\begin{array}{l}\text { Comparisons } \\
\text { across four grades, } \\
p=0.03\end{array}$ & $\begin{array}{l}\text { Comparisons } \\
\text { across four } \\
\text { groups, } \\
\mathrm{p}=0.28\end{array}$ & $\begin{array}{l}\text { Comparisons } \\
\text { across four groups, } \\
p=0.73\end{array}$ & $\begin{array}{l}\text { Comparisons } \\
\text { across four } \\
\text { groups, } \\
p=0.07\end{array}$ & $\begin{array}{l}\text { Comparisons } \\
\text { across four } \\
\text { grades, } \\
p=0.72\end{array}$ & $\begin{array}{l}\text { Comparisons } \\
\text { across four } \\
\text { groups, } \\
p=0.72\end{array}$ \\
\hline
\end{tabular}

B $\quad 1.03(0.73$ to 1.44$) \quad 0.95(0.71$ to 1.26$) 1.27(0.83$ to 1.96$) \quad 1.04$ (0.84 to 1.28$) 0.95$ (0.57 to 1.60$) 0.72$ (0.20 to 2.56$)$

C $\quad 0.67(0.44$ to 1.02$) \quad 1.27(0.82$ to 1.97$) 0.99(0.51$ to 1.93$) \quad 0.96$ (0.71 to 1.30$) 1.06$ (0.37 to 3.05$) 1.73$ (0.44 to 6.75$)$

1.27 (0.88 to 1.84$) \quad 1.44$ (0.92 to 2.24$) 1.15$ (0.60 to 2.23$) \quad 1.32$ (0.98 to 1.77$) 1.42$ (0.66 to 3.03$) 0.67$ (0.08 to 5.60$)$

Comparisons

across four groups, $\mathrm{p}=0.83$

$0.89(0.55$ to 1.46$)$ $0.82(0.36$ to 1.88$)$

1.15 (0.59 to 2.24$)$

$\mathrm{B} 5$, back 5; FR, front row; $\mathrm{H}$, halves; IB, inside backs; IRR, incidence rate ratio; $\mathrm{OB}$, outside backs; U13, rugby players $<13$ years; U15, rugby players $<15$ years; U18, rugby players $<18$ years; $U 20$, rugby players $<20$ years.

Values are IRR $(95 \% \mathrm{CI})$.

rate increased, which was observed by Quarrie et al in an overlapping age range (U17 to $>23$ years) ${ }^{23}$ Inside backs had a significantly higher rate of missed game injury than other player positions. Quarrie et al also observed the backs, albeit the midfield backs, to miss more of the season because of injury than other player positions. ${ }^{23}$ When the subset of $\mathrm{H} / \mathrm{F} / \mathrm{N}$ injuries was examined, different risk factors emerged for player position and level. The trend of increasing injury incidence with level was observed for all and H/F/N injury.

Halves had the highest rate of head injury with outside backs having the highest rate of missed game head injury (ie, greatest risk). The back five had a significantly higher rate of facial injury than all other players. The front row had the greatest rate of neck injury, and forwards generally had a twofold higher rate of neck injury than backs. The U13 age group had the lowest rates of head and facial injury, and the U20 age group had the lowest rate of neck injury resulting in a missed game, but the differences were not significant.

Contact phases of rugby - that is, the tackle, other impacts and scrums-accounted for $78 \%$ of all $\mathrm{H} / \mathrm{F} / \mathrm{N}$ injury, which is not surprising, as $\mathrm{H} / \mathrm{F} / \mathrm{N}$ injury generally results from impact. This confirms the results of other studies in the UK and Australia that have shown that the tackle has the greatest risk of injury. ${ }^{29} 30$ There was a slightly higher proportion of U13s injured while being tackled compared with tackling (33\% and $25 \%$, respectively), and this is reversed with U15s (13\% and $40 \%$, respectively). This may be related to skill, player size and game speed developments. While the scrum accounted for $4 \%$ of all $\mathrm{H} / \mathrm{F} / \mathrm{N}$ injuries, it accounted for $14 \%$ of all neck injuries.

Stature and body mass data presented in online only supplementary table 1 show that mean body mass increased by $15 \mathrm{~kg}$ from the U13 age group to the U15 age group, a further $9 \mathrm{~kg}$ in the $\mathrm{U} 18$ age group, and a further $10 \mathrm{~kg}$ in the U20 age group. Stature increased from $161 \mathrm{~cm}$ in the U13 age group to $181 \mathrm{~cm}$ in the U20 age group, with an average increase of $14 \mathrm{~cm}$ from age groups U13 to U15. Junge et al reported the mean stature and body mass for their cohort of 16-18-year-old New Zealand rugby players to be $1.78 \mathrm{~m}$ and $82.5 \mathrm{~kg}$, respectively, which are very similar to our U18 sample. ${ }^{19}$ Increases in body mass coupled with increases in strength and speed, may account for the increased rate of injury associated with level of play, as observed by Quarrie et al. ${ }^{23}$ Unfortunately, the data cannot answer the perennial question of whether large-for-age boys participating with average or small-for-age boys is an injury risk factor. To do this, a distinctly different analysis is required that examines injuries in contact and non-contact rugby events, while considering the body masses of all players involved in each event, each player's role in the event-for example, tackler or ball carrier, the biomechanics of the event, and after controlling for age and level of play. Nonetheless, the data do provide a baseline for comparison to examine whether an individual's body mass is within $95 \%$ norms for players in this age group.

Table 3 Main events causing head, neck and facial injury in rugby

\begin{tabular}{|c|c|c|c|c|c|}
\hline \multirow[b]{2}{*}{ Game event } & \multicolumn{4}{|c|}{ Level of play } & \multirow[b]{2}{*}{ All } \\
\hline & U20 & U18 & U15 & U13 & \\
\hline Tackling & $24(24)$ & $22(35)$ & $30(40)$ & $25(25)$ & $26(28)$ \\
\hline Being tackled & $25(20)$ & $23(35)$ & $23(13)$ & $25(33)$ & $26(23)$ \\
\hline Other impact & 22 (15) & $21(6)$ & 19 (14) & $13(8)$ & $22(13)$ \\
\hline Scrum & $3(11)$ & $3(12)$ & $4(13)$ & $10(25)$ & $4(13)$ \\
\hline All others & $26(30)$ & 31 (12) & $24(20)$ & 27 (9) & $22(23)$ \\
\hline
\end{tabular}

$\mathrm{U} 13$, rugby players $<13$ years; U15, rugby players $<15$ years; U18, rugby players $<18$ years; U20, rugby players $<20$ years.

Values are percentages. Values in parentheses are percentages of neck injuries associated with the phase. The "all other" category includes jumping in line out, slip/ trip, twisting, collision with fixed object and rucking. 
Risk factors that could be studied in the future would focus on skill acquisition, development and execution, physical maturation, anatomical features, player and game "speed" in youth rugby. These would contribute to a study of the "inciting event" and "internal risk factors" as proposed by Bahr and Krosshaug. ${ }^{31}$

Overall, injury rates for young players (U13 and U15) are lower than in the adult and professional levels of rugby, and the sport is not as "dangerous" as may be perceived by some parents; perceptions that might arise via professional rugby. However, other studies have found that there is a significantly higher rate of injury in rugby compared with other popular youth sports-for example, a 2.7-fold rate of injury in U18's rugby compared with a similar age group of soccer players ${ }^{19}$ and a lower rate of concussion in soccer than rugby. ${ }^{32}$ This study reinforced that there is a higher incidence of $\mathrm{H} / \mathrm{F} / \mathrm{N}$ injury in youth rugby compared with youth soccer. In high school sports in the USA, Powell et al observed that soccer had a lower rate of traumatic brain injury than American football, but non-contact ball sports, such as basketball and baseball, had even lower rates of traumatic brain injury. ${ }^{33}$ The results indicate that team football sports can be made "safer", by adopting non-contact variants, such as touch football.

\section{Catastrophic injury and injury management}

The two events leading to neck injuries described in detail could have resulted in catastrophic consequences. This highlights that it is important to capture injury data and analyse them for the potential consequences, rather than simply measuring "catastrophic injury". Measurement and reporting of a set of cervical injuries, their causes and management, in addition to long-term function and impairment, is preferential to focussing only on impairment. A more comprehensive approach may identify more clearly risk factors than the analysis of relatively infrequent events, such as spinal cord injury. Our data suggest that the scrum, in general, is a cause of neck injury, especially for the front row, not just spinal cord injury. The two serious neck injuries, however, were caused in a ruck and a tackle. While the cause and prevention of neck injuries in the tackle or other contact situations should not be ignored, as they are more frequent game events, neck injuries in the scrum and to the front row are of great concern, especially when it is considered that all teams except the U20 played with U19 scrum rules.

With regards to the two detailed spine injuries, management was suboptimal. Neither person was immobilised. Both players were transported to the hospital in a private car. Education of team staff and an acute injury management policy is warranted. While no specific data were obtained on concussion management and return-to-play decisions, it was our observation that this was not conducted according to current best practice, and this may be reflected in the rapid return to play. ${ }^{7}$

\section{Injury surveillance}

The collection of injury data over two seasons provided an opportunity to reflect upon the new consensus guidelines for injury data collection in rugby. ${ }^{18}$ In contrast to professional sport, the level of medical coverage at the game and training is often minimal at youth and community levels. Recreational players attend fewer compulsory team sessions per week than professionals, and this makes data collection on discrete time divisions, such as returned-to-play within 2 days, difficult. For risk factor or intervention studies in non-professional rugby, it may be too difficult to study sufficiently powered samples and detailed

\section{What is already known on this topic}

Head injury accounts for up to $30 \%$ of rugby injury. Catastrophic spinal injury occurs in rugby but is rare. Differences in injury recording systems have made comparisons between sports injury studies difficult. Injury risks in professional rugby have been identified.

\section{What this study adds}

The study reports on the incidence of $H / F / N$ injury in youth rugby using standard methods. Injury risks are lower in youth rugby than professional rugby. The forwards had the highest rate of neck injury and inside backs had the highest rate of injuries causing the player to miss a game. Contact events, including the scrum and tackle, were the main events leading to injury.

samples without massive resources. The broader definitions of injury severity - for example, game and missed game injury, are therefore useful and can map to the consensus guidelines. Studies of the clinical manifestation of concussion-for example, using neuropsychological measures, may also not easily fit into the guidelines, as they require a specific timeline for tests and "normal" is not return to play, but return to baseline. With sufficient resources and with appropriate research questions, a standard set of injury data that conform to the consensus guidelines could be collected in parallel with data that are research question-focussed in contrast to injury audits.

\section{CONCLUSIONS}

In conclusion, $\mathrm{H} / \mathrm{F} / \mathrm{N}$ injuries are of concern in youth sports because of the risk of associated transient or permanent impairments. Young boys playing rugby are not at a high risk of $\mathrm{H} / \mathrm{F} / \mathrm{N}$ injury, but this increases with age within youth rugby and in certain player positions. Contact events and the scrum are areas of the game that require ongoing attention through rules, skill analysis and development and equipment in order to reduce the risk of $\mathrm{H} / \mathrm{F} / \mathrm{N}$ injuries. Injury management, both acute and pertaining to return to play are also areas that require attention in youth rugby.

Acknowledgements: This project was funded by the International Rugby Board (IRB). CF was funded by an NHMRC Principal Research Fellowship. The investigators were solely responsible for decisions regarding the design and conduct of the study, as well as collection, management, analysis and interpretation of the data. The authors prepared this manuscript, and it was sent to the IRB for approval. All authors and researchers are independent of the International Rugby Board, and the project was conducted independently. Statistical analyses were conducted in part by Dr Rory Wolfe from Monash University. Dr J P Best and Associate Professor D Chalmers were investigators on the randomised controlled trial of headgear. The authors would like to thank the following research assistants on the project: Ms M Romiti, Dr D Twomey, Mr C French and Mr T Savage. Thanks go to Mr John Searl from the Australian Rugby Union who liaised with the ARU and rugby clubs. Many other people contributed to the execution of the project-for example, primary data collectors, club/school personnel, team staff and medical personnel. We gratefully acknowledge their contributions.

Competing interests: None.

Ethics approval: The study was approved by The University of New South Wales Human Research Ethics Committee.

Patient consent: Obtained.

\section{REFERENCES}

1. Brooks JH, Fuller CW, Kemp SP, et al. Epidemiology of injuries in English professional rugby union: part 1 match injuries. Br J Sports Med 2005;39:757-66. 
2. Best JP, Mclntosh AS, Savage TN. Rugby World Cup 2003 Injury Surveillance Project. Br J Sports Med 2005;39:812-17.

3. Fuller CW, Brooks JH, Kemp SP. Spinal injuries in professional rugby union: a prospective cohort study. Clin J Sport Med 2007;17:10-16

4. Bathgate A, Best JP, Craig G, et al. A prospective study of injuries to elite Australian rugby union players. Br J Sports Med 2002;36:265-9.

5. Kelly JP. Traumatic brain injury and concussion in sports. JAMA 1999;282:989-91.

6. Collins $\mathbf{M}$, Lovell MR, Iverson GL, et al. Examining concussion rates and return to play in high school football players wearing newer helmet technology: a three-year prospective cohort study. Neurosurgery 2006;58:275-86.

7. McCrory P, Johnston K, Meeuwisse W, et al. Summary and agreement statement of the 2nd International Conference on Concussion in Sport, Prague 2004. Br J Sports Med 2005;39:196-204.

8. McIntosh AS, McCrory P. Preventing head and neck injury. Br J Sports Med 2005:39:314-18.

9. Garraway WM, Macleod D. Epidemiology of rugby football injuries. Lancet 1995;345:1485-7.

10. Davidson RM, Schoolboy rugby injuries, 1969-1986. Med J Aust 1987; 147:119-20.

11. Bird YN, Waller AE, Marshall SW, et al. The New Zealand Rugby Injury and Performance Project: V. Epidemiology of a season of rugby injury. Br J Sports Med 1998;32:319-25.

12. Sparks JP. Half a million hours of rugby football. The injuries. Br J Sports Med 1981;15:30-2.

13. Quarrie KL, Cantu RC, Chalmers DJ. Rugby union injuries to the cervical spine and spinal cord. Sports Med 2002;32:633-53.

14. Carmody DJ, Taylor TK, Parker DA, et al. Spinal cord injuries in Australian footballers 1997-2002. Med J Aust 2005:182:561-4.

15. Browne GJ. Cervical spinal injury in children's community rugby football. Br J Sports Med 2006:40:68-71.

16. McIntosh AS. Rugby injuries. Med Sport Sci 2005;49:120-39.

17. Boufous S, Finch CF, Bauman A. Parental safety concerns - a barrier to sport and physical activity in children? Aust N Z J Public Health 2004;28:482-6.

18. Fuller CW, Molloy MG, Bagate $C$, et al. Consensus statement on injury definitions and data collection procedures for studies of injuries in rugby union. $\mathrm{Br} J$ Sports Med 2007:41:328-31.
19. Junge A, Cheung $K$, Edwards $T$, et al. Injuries in youth amateur soccer and rugby players-comparison of incidence and characteristics. Br J Sports Med 2004;38:168-72.

20. Durie RM, Munroe AD. A prospective survey of injuries in a New Zealand schoolboy rugby population. NZ J Sports Med 2000;28:84-90.

21. Agel J, Dompier TP, Dick $\mathrm{R}$, et al. Descriptive epidemiology of collegiate men's ice hockey injuries: National Collegiate Athletic Association injury surveillance system, 1988-1989 through 2003-2004. J Athl Train 2007:42:241-8.

22. Agel J, Evans TA, Dick $R$, et al. Descriptive epidemiology of collegiate men's socce injuries: National Collegiate Athletic Association injury surveillance system, 19881989 through 2002-2003. J Athl Train 2007;42:270-7.

23. Quarrie KL, Alsop JC, Waller AE, et al. The New Zealand rugby injury and performance project. VI. A prospective cohort study of risk factors for injury in rugby union football. Br J Sports Med 2001;35:157-66.

24. McIntosh AS, McCrory P, Finch CF, et al. Is protective headgear effective in rugby union football? The results of a randomised controlled trial. The 7th world conference on injury prevention and safety promotion, Vienna, 2004

25. Finch CF. An overview of some definitional issues for sports injury surveillance. Sports Med 1997;24:157-63.

26. Hagglund M, Walden M, Bahr R, et al. Methods for epidemiological study of injuries to professional football players: developing the UEFA model. Br J Sports Med 2005;39:340-6.

27. Checkoway H, Pearce N, Kriebel D. Research methods in occupational epidemiology. 2nd edn. New York: Oxford University Press, 2004.

28. Murray DM. Design and analysis of group-randomized trials. New York: Oxford University Press, 1998

29. Fuller CW, Brooks JH, Cancea RJ, et al. Contact events in rugby union and their propensity to cause injury. Br J Sports Med 2007:41:862-7.

30. McIntosh AS, Savage TN, Nicholson A. Investigating the tackle in Rugby Union. Proceedings of the Australian Conference of Science and Medicine in Sport; Melbourne, 2005.

31. Bahr R, Krosshaug T. Understanding injury mechanisms: a key component of preventing injuries in sport. Br J Sports Med 2005;39:324-9.

32. Koh J0, Cassidy JD, Watkinson EJ. Incidence of concussion in contact sports: a systematic review of the evidence. Brain Inj 2003;17:901-17.

33. Powell JW, Barber-Foss KD. Traumatic brain injury in high school athletes. JAMA 1999:282:958-63. 